\title{
O lugar da moda em A Illustração e no Le Monde Illustré: diálogos e apropriações
}

The place of fashion in A Illustration and Le Monde Illustré: dialogues and appropriations

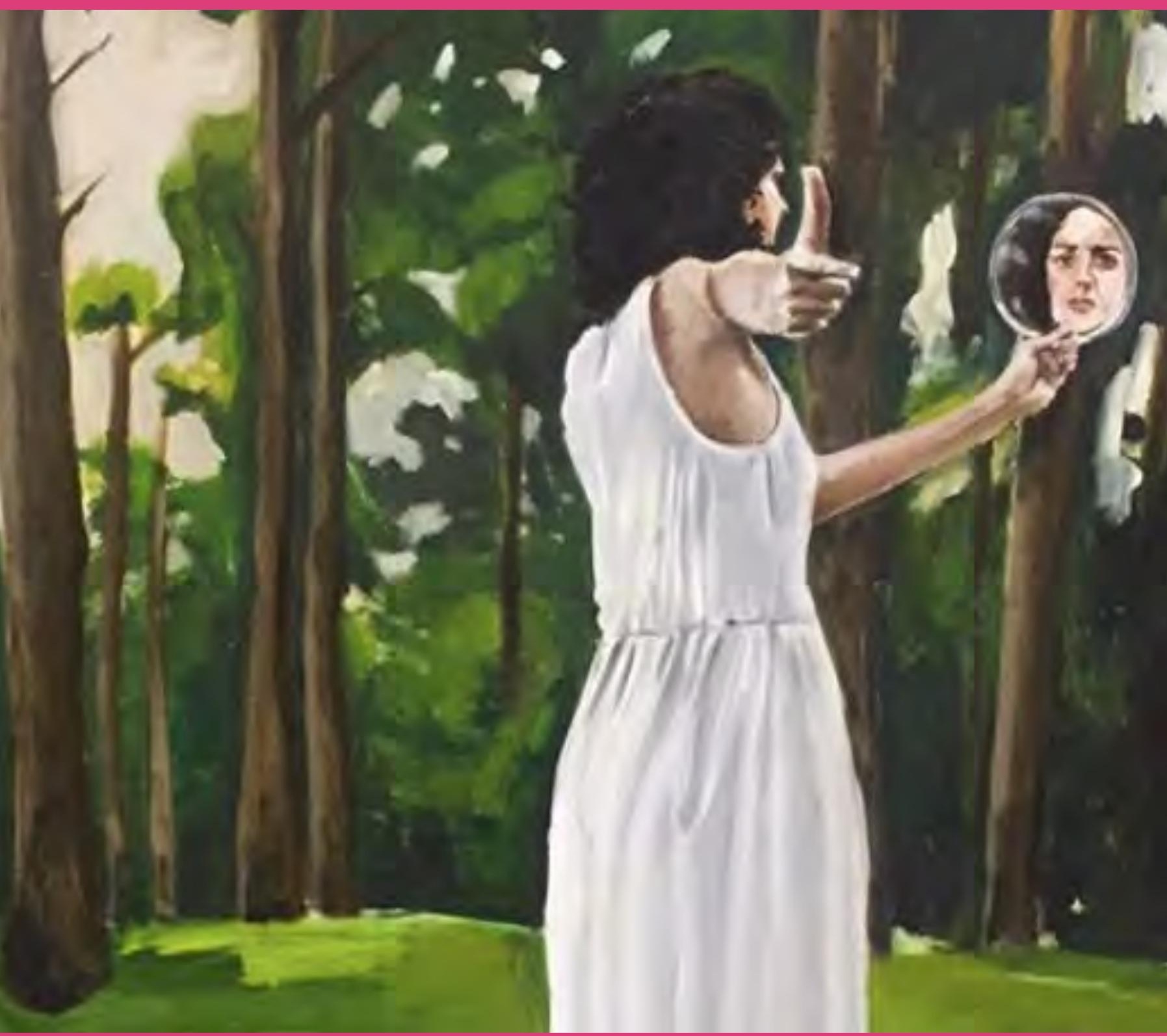




\section{Tania Regina de Luca ${ }^{1}$}

ORCID: https://orcid.org/0000-0002-8942-5237

[resumo] Neste artigo, a atenção concentra-se no conteúdo de moda difundido pela $A$ Illustração (Paris, 1884-1892), publicação que circulava em Portugal e no Brasil, mas que mantinha estreitas relações com a francesa Le Monde Illustré (Paris, 1857-1940). Trata-se de verificar os intercâmbios entre esses impressos nas seções dedicadas à moda. A análise desse material coloca questões instigantes a respeito da circulação de imagens, da noção de autoria e do compartilhamento de um imaginário comum sobre as noções de moda e elegância. Cumpre destacar que as chamadas "ilustrações" compunham um setor específico dos periódicos, cuja origem remonta a meados do século XIX.

[palavras-chave] Revistas ilustradas. Moda. Projeto gráfico. Circulação de imagens e textos.

[abstract] In this article, attention focuses on the fashion content disseminated by A Illustração (Paris, 1884-1892), a periodical that circulated in Portugal and Brazil, but which maintained close relations with the French Le Monde Illustré (Paris, 1857-1940). The objective is to verify the exchanges between these publications regarding the section dedicated to fashion. The analysis of this material poses thought-provoking questions about the circulation of images, the notion of authorship and the sharing of a common imaginary about the notions of fashion and elegance. It is worth highlighting that the so called "illustrations" made up a specific sector of the periodicals, whose origin dates back to the mid-nineteenth century.

[keywords] Illustrated magazines. Fashion. Graphic design. Circulation of texts and images.

Recebido em: 13-01-2019

Aprovado em: 04-07-2019

\footnotetext{
${ }^{1}$ Livre-docente no curso de pós-graduação em História da Unesp (Assis). E-mail: tania.luca@unesp.br. Lattes: http://lattes.cnpq.br/4332049365505182
} 
O objetivo deste texto é discutir o lugar ocupado pelo conteúdo de moda nas páginas da revista $A$ Illustração (Paris, 1884-1892)², que mantinha relações muito próximas com a publicação francesa Le Monde Illustré (Paris, 1857-1940). A escolha justifica-se pelas características e pelo layout da página da seção dedicada à moda, inovadores em relação ao padrão de composição gráfica dominante nesse tipo de publicação, genericamente denominadas de "ilustrações", bem como pela procedência do conteúdo textual e visual ofertado aos leitores luso-brasileiros, que permite refletir sobre a circulação de informações no espaço transatlântico.

\section{A Illustração e o Le Monde Illustré}

Na segunda metade do século XIX ocorreu a difusão de um tipo bastante específico de periódico genericamente denominado de "ilustrações". A novidade não residia no fato de essas publicações trazerem material iconográfico, já presente em revistas lançadas em décadas precedentes, mas no abandono da preocupação com os conhecimentos úteis em prol de dar conta de fatos e acontecimentos contemporâneos, as atualidades. 0 que se ofertava aos assinantes era uma mescla entre crônica mundana, cultural e política com uma menção a eventos ocorridos ao redor do globo, notas sobre lugares recônditos, passamento de figuras ilustres, descobertas científicas, novidades nos campos literário, musical, teatral, artístico e esportivo, faits divers, enfim, um conjunto eclético que podia ser reunido graças ao desenvolvimento dos meios de transporte, à aceleração da circulação das informações e ao crescente processo de urbanização das grandes capitais europeias, o que tornava a notícia um bem precioso e necessário.

Ainda que estivessem disponíveis meios mecânicos de captura de imagens, a tecnologia para reprodução direta das fotografias nos impressos periódicos apenas se difundiu largamente na passagem para o Novecentos, circunstância que colocou uma série de desafios para a produção das belas estampas que ocupavam cerca de metade das 16 páginas que compunham essas publicações, que tiveram no The Illustrated London News (1842) seu modelo matricial, replicado ao redor do mundo, a começar pela francesa L'Illustration (1843), logo seguida por outras, em diferentes parte do globo. Esses periódicos luxuosos, com formato in quarto, texto distribuído em três colunas e relativamente caros $^{3}$, esmeravam-se em fornecer um produto bem-feito do ponto de vista gráfico, recheado com imagens de grandes dimensões e que se destacavam pelo "acabamento artístico", para retomar um termo recorrentemente utilizado. Eles difundiam uma recolha

\footnotetext{
A publicação teve vários subtítulos. 0 primeiro deles, "Revista quinzenal para Portugal e o Brasil", manteve-se inalterado ao longo de 1884 para oscilar, durante o ano seguinte, entre números sem subtítulo e outros no qual se utilizou a designação "Revista universal impressa em Paris". Entre dezembro de 1885 e julho de 1887, vigorou a fórmula "Revista de Portugal e do Brasil", sendo que, daí em diante, os subtítulos foram abolidos.

Sobre o preço das publicações deste gênero, ver: CHARLE, 2004, p. 10.
} 
amena e pitoresca do que se passava no planeta e era comum encontrá-los adornando salas e bibliotecas burguesas ${ }^{4}$.

Portugal e Brasil enfrentavam dificuldades para produzir, com o mesmo padrão de qualidade e por preços competitivos, esse gênero de impresso e foi justamente o estabelecimento de rotas transatlânticas seguras, os baixos custos de impressão na França e a existência de um mercado de matrizes já utilizadas, vendidas a preços módicos, que levou o empresário Elísio Mendes, português que vivia entre Lisboa e o Rio de Janeiro, familiarizado com o mundo dos impressos e um dos proprietários do matutino Gazeta de Notícias (Rio de Janeiro, 1875-1942) e da tipografia que imprimia o jornal, a aí vislumbrar uma boa oportunidade de negócio.

Assim, ele colocou em marcha a fundação de uma publicação produzida nas oficinas da Société Anonyme de Publications Périodiques, importante empresa francesa que, entre vários outros títulos, era a responsável pela edição do Le Monde Illustré, publicação que concorria com a L'Illustration. A empresa francesa não apenas se responsabilizava por imprimir o periódico, que seguia padrão idêntico ao do Le Monde Illustré em termos de formato e número de páginas, como fornecia o material iconográfico, que se constituía na pedra de toque desse tipo de impresso. A Société lucrava, pois recolocava em circulação estampas que já não lhe interessavam e ainda vendia seus serviços tipográficos, enquanto os responsáveis pela A Illustração ofereciam ao público luso-brasileiro um produto sofisticado e por preços equivalentes aos periódicos produzidos em Lisboa ou no Rio de Janeiro, o que acabava por resultar em um custo final relativamente mais baixo do que o alcançado no exemplar vendido na França.

É certo que tal arranjo aponta para um indivíduo que conhecia muito bem os meandros da atividade e que tinha sólidos laços com o mundo dos impressos periódicos, fosse no Brasil, já que estava à frente de um importante matutino, fosse em Portugal, onde mantinha proximidade com o destacado editor David Corazzi. Elísio era, antes de tudo, um empresário e não um homem de letras, razão pela qual delegou a responsabilidade da redação do projetado periódico ao correspondente do seu jornal em Paris, o jovem português Mariano Pina (1860-1899), admirador e próximo de Eça de Queirós e de Ramalho Ortigão, ambos colaboradores assíduos da Gazeta de Notícias ${ }^{5}$.

Em maio de 1884, veio a público o primeiro número do quinzenário A Illustração, distribuída em Portugal por Corazzi e, no Brasil, pela Gazeta. É interessante notar que, nas

\footnotetext{
4 "A casa é ainda o território por meio do qual os proprietários tentam apropriar a natureza pela exuberância dos jardins e das estufas, onde as estações são abolidas, a arte pelo acúmulo de coleções ou pelo menos concertos privados, o tempo pelas lembranças da família ou pelas viagens, o espaço pelos livros que descrevem o planeta e pelas revistas ilustradas - de L'Illustration a Lectures pour tous ou Je sais tout - que o exibem. A leitura, exploração sedentária, é uma maneira de apropriar o universo ao torná-lo legível e, por meio da foto, visível. A biblioteca abre a casa para o mundo; encerra o mundo dentro da casa. Manifesta-se, na virada do século, um louco desejo de intervenção e domínio do mundo pela casa" (PERROT, 2009, p. 287-288).

Graças ao espólio dos irmãos Augusto e Mariano Pina, depositado na Biblioteca Nacional de Portugal, é possível conhecer detalhes do funcionamento interno do quinzenário por meio da correspondência do diretor e outros documentos conservados, a exemplo de alguns contratos de impressão.
} 
páginas da revista, a participação de Elísio Mendes nunca foi mencionada, ou seja, ele permaneceu como investidor oculto. Apenas no catálogo de 1884 da Casa Editora Horas Românticas, de Corazzi, seu nome foi evocado para atestar ao público português a seriedade do empreendimento, enquanto a propaganda levada a efeito nas páginas do matutino brasileiro insistia em atribuir toda a responsabilidade apenas a Pina. Foi somente em dezembro de 1885, quando Elísio saiu do negócio, que o até então diretor passou a diretor-proprietário, condição mantida até o fechamento do impresso, em janeiro de 1892. A publicação somou 184 exemplares sem qualquer interrupção na sua circulação ${ }^{6}$.

A análise das páginas de $A$ Illustração revelou que quase $80 \%$ das estampas presentes na revista luso-brasileira já haviam figurado no Le Monde Illustré, enquanto cerca de 13\% compunham-se de material especialmente confeccionado para A Illustração, provindo o restante de outros periódicos europeus. Tal circunstância está longe de ser irrelevante uma vez que convida a refletir sobre processos de formação de gostos e sensibilidades, padrões estéticos e difusão de condutas, hábitos e valores em âmbito transatlântico, já que os leitores franceses e os lusófonos tinham acesso simultâneo ao mesmo rol de imagens.

Vale destacar que cada estampa era comentada na seção "As nossas gravuras", que tinha a missão de contextualizar o material visual, justificar escolhas e, em um empreendimento que se afigura redundante ao observador contemporâneo, descrevê-lo. Por vezes, também havia menções à procedência e à(s) autoria(s), sempre chamando a atenção do leitor para a qualidade estética do que se ofertava, fruto de um trabalho artesanal feito por desenhistas e gravadores. É importante ter presente que havia separação física entre as estampas e as notas explicativas, ou seja, a iconografia não cumpria a função de ilustrar os escritos e tampouco se tratava de um sistema textual e icônico nos moldes das reportagens fotográficas que se imporiam na passagem do século XIX para o XX, opção que não pode ser explicada por limitação de ordem técnica, uma vez que se tratavam de matrizes em relevo, fossem xilogravuras ou clichês.

O projeto editorial desse tipo de revista ilustrada sempre esteve ancorado na difusão de estampas que foram, contudo, ganhando dimensões e detalhamento, tanto que chegaram a ocupar uma ou mesmo duas páginas inteiras, como se observa, por exemplo, na figura 1, que ocupava as duas páginas centrais, ou seja, com quase $60 \mathrm{~cm}$ de largura. Nesses casos, era comum que o verso permanecesse em branco, o que abria a possibilidade de o leitor retirar a estampa sem comprometer o conteúdo. A acirrada competição entre esse gênero de impresso acabou por estabelecer um nexo entre a quantidade e o tamanho das estampas de um lado e o prestígio da publicação de outro, o que justificava a mobilização do adjetivo “artístico" para definir e enobrecer o conteúdo iconográfico que, de fato, exigia a intervenção de profissionais muito habilidosos.

${ }^{6}$ Para um estudo sistemático da revista, ver: LUCA, 2018. 


\section{FIGURA 1 - PÁGINAS CENTRAIS DA REVISTA OCUPADAS POR ESTAMPA}

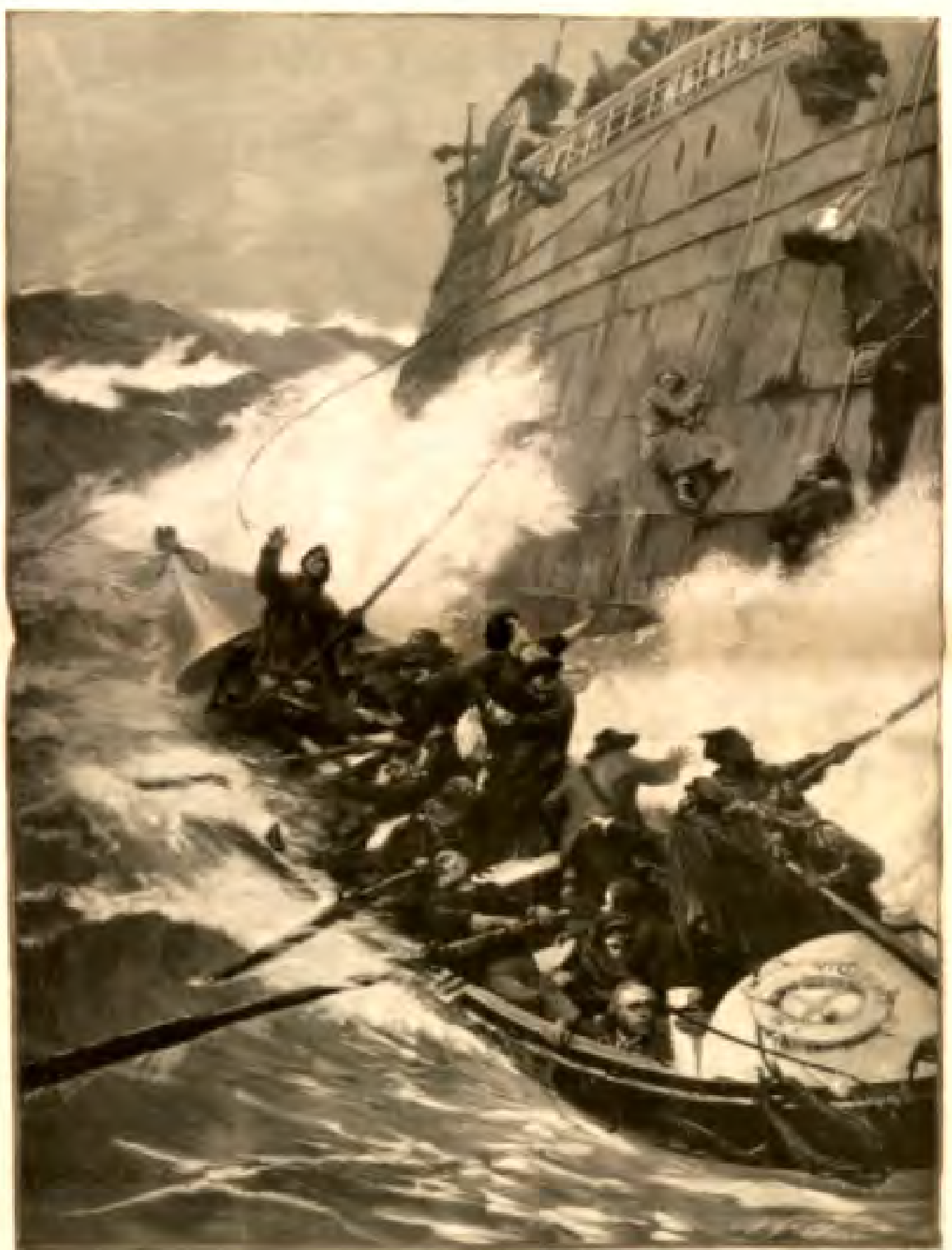

FONTE: A Illustração, ano 7, n. 16, p. 49-50, 20/8/1890. Biblioteca da FCL/Unesp (Assis). Para o Le Monde Illustré, ver: https://gallica.bnf.fr/ark:/12148/bpt6k6377481v/f12. Acesso em: jun. 2019. 
Se na década de 1840, momento do surgimento desses periódicos, as estampas ainda ilustravam os textos, esse liame já havia sido rompido quando do lançamento de A Illustração, em 1884. Tal característica acabou por se tornar a marca distintiva desses impressos, que competiam no sentido de ofertar aos leitores imagens cada vez maiores e mais detalhadas, o que acabou por selar a separação física entre a pena e o lápis, isto é, a parte textual e a visual.

No que respeita à primeira, que compunha metade da revista, havia artigos avulsos e seções fixas, entre elas "Crônica”, a cargo de Pina e que fazia as vezes de editorial. No conjunto, predominavam produções e discussões de cunho literário em sintonia com a atuação do seu diretor no campo cultural.

\title{
A moda em A Illustração: primeira ocorrência (1885)
}

A moda não ocupou lugar de destaque n'A Illustração, o que não significa, porém, que o tema estivesse totalmente ausente. A primeira referência direta ocorreu em abril de 1885, quando a publicação estava prestes a completar seu primeiro ano de circulação. Uma nota da redação prometia às leitoras "uma verdadeira novidade, uma nova seção":

\begin{abstract}
Esta nova seção é exclusivamente feminina, é a última novidade num grande ramo da indústria parisiense, a última novidade em artigos que todas as damas desejam conhecer, mas a última novidade desenhada a capricho, um desenho escrupuloso e elegantíssimo, como se não encontra igual em publicações especiais. Não quiséramos dar hoje mais algumas explicações às nossas leitoras - mas desejamos fazer surpresa para o próximo número, e é para o próximo número que chamamos a atenção do nosso público feminino ${ }^{7}$. (A ILLUSTRAÇÃO, 1885, p. 126)
\end{abstract}

A despeito das promessas e do esforço para dotar de excepcionalidade a proposta, o resultado foi bastante modesto, pois a tão decantada seção acabou por se efetivar em apenas dois números, aliás distantes no tempo: uma ocorrência em maio e outra em setembro de 1885.

A edição de maio trouxe a seção "As últimas modas de Paris". Tratava-se de dois modelos acompanhados de legendas descritivas bastante genéricas e que ocupavam pouco mais da metade de uma página (ver figura 2). No texto relativo à seção, publicado em "As nossas gravuras", os vestidos não foram referidos, com a ênfase recaindo na "execução artística" e na "escolha do assunto"8. Estava em jogo o distanciamento dos jornais de moda, aos quais se relegava o papel de meros divulgadores das novidades das lojas - Louvre, Le Bon Marché e Printemps. Em A Illustração, bem ao contrário, ofertava-se

\footnotetext{
Uma novidade. A Illustração, ano 2, n. 8, p. 126, 20 abr. 1885.

${ }^{8}$ As últimas modas de Paris. As nossas gravuras. A Illustração, ano 2, n. 9, p. 134, 5 maio 1885.

As citações subsequentes do parágrafo provêm dessa fonte.
} 
a "atualidade mundana, exclusivamente parisiense", ou seja, "toilettes particulares que obtiveram sucesso ou na vitrine de uma grande modista, ou num baile particular de aristocratas ou de artistas, ou sobre o palco de um teatro". Pretendia-se, portanto, oferecer "a moda artística, a moda elegante por excelência". E era justamente nessa escolha que se procurava estabelecer a distância com outras publicações de moda, como se fez questão de explicitar:

\footnotetext{
De uma toilette riquíssima que uma princesa encomende a uma modista célebre de Paris daremos logo um desenho; de uma toilette que mais brilhou num baile que os jornais apregoem, também daremos o desenho; não escapando à atenção de nossos colaboradores especiais nem as mais formosas toilettes de atrizes célebres, feitas para peças que obtenham sucesso, nem o desenho tipo da toilette da estação parisiense. É a moda artística, a moda elegante por excelência que a Illustração vai oferecer às suas leitoras. (A ILLUSTRAÇÃO, 1885, p. 134)
}

Esses comentários, feitos no interior de "As nossas gravuras" e sem relação direta com as estampas, levantam dúvidas sobre o grau de autonomia da tão prometida e incensada seção que, afinal, permaneceu no campo das intenções.

Apenas em setembro registrou-se a segunda ocorrência, nos mesmos moldes da anterior, não sem menção à supostas reclamações: "Muitas das nossas leitoras escreveram-nos, admiradas da sem-cerimônia com que tínhamos prometido uma seção regular, a que logo faltamos". Tampouco faltaram as protocolares desculpas da redação - "uma grande abundância de matérias obrigou-nos, com grande pesar nosso, a retardar de alguns números a nossa prometida seção de modas" - e novas promessas - "a Illustração recomeça a dar em todos os números um desenho da última novidade parisiense em toilettes de senhoras" - que também permaneceram letra morta. Dessa vez, a seção veio no singular, "A última moda de Paris", quiçá por se tratar de apenas um modelo. Note-se que não havia legenda, apenas a remissão para a página na qual se encontravam os comentários (figura 3). Esses, por seu turno, eram bastante sintéticos, pois, além das justificativas acima reproduzidas, pouco havia sobre a questão da moda em si: "A gravura que hoje damos representa uma toilette muito na moda na praia de Trouville e de Dieppe: Meia saia em estamina azul marinho sobre uma saia azul, com pregas no corpete. A meia saia termina em ponta e a mesma forma é repetida no corpete". 9

\footnotetext{
9 A última moda de Paris. A Illustração, ano 2, n. 17, p. 262-263, 5 set. 1885. Todos os trecos citados nesse parágrafo provém desta fonte.
} 

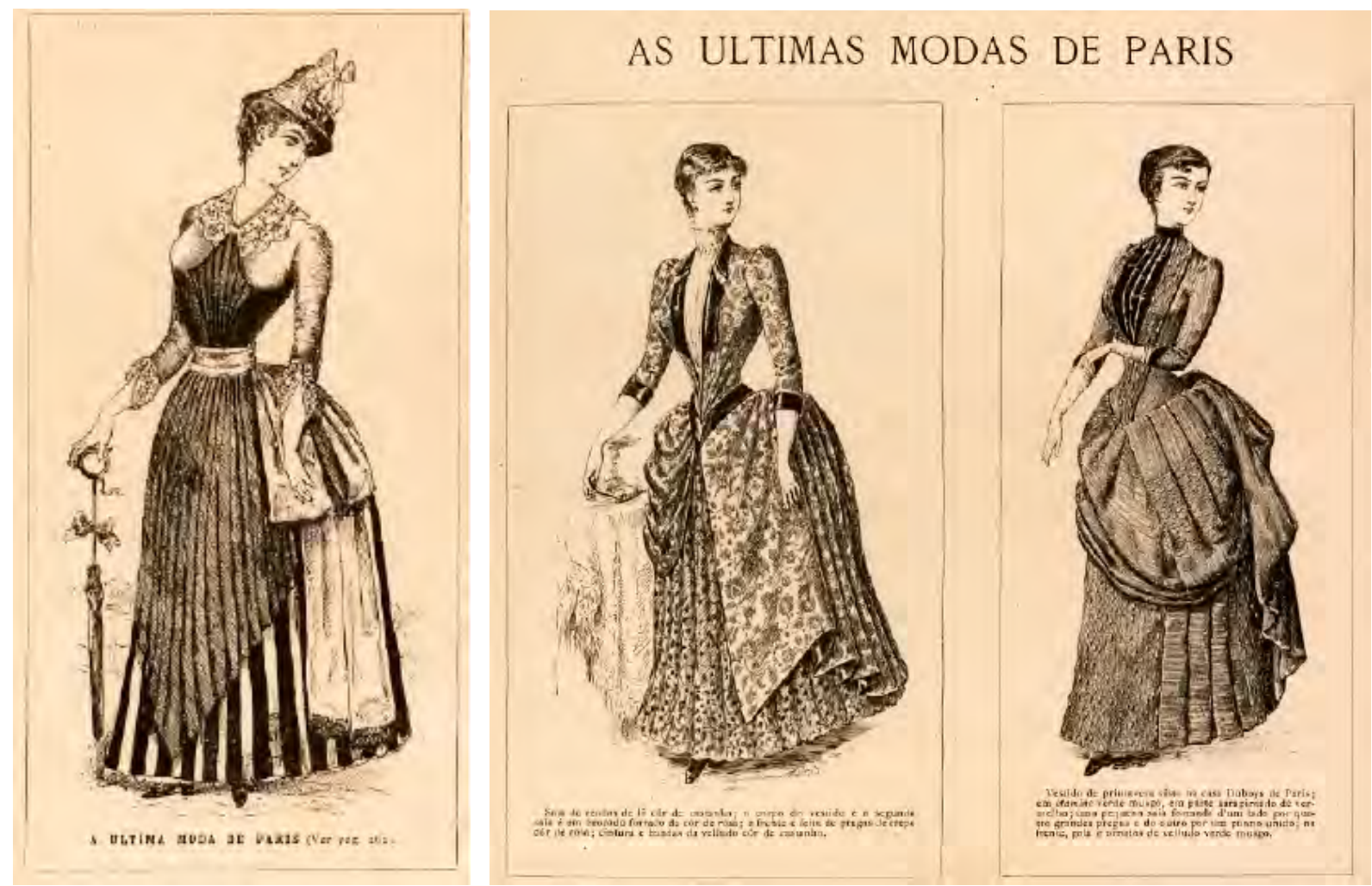

FONTE: A Illustração, ano 2, n. 9, p. 140, 5/5/1885 e A Illustração, ano 2, n. 17, p. 268, 5/9/1885. Biblioteca da FCL/Unesp (Assis). Nas legendas publicadas em maio de 1885, lê-se: "Saia de rendas de lã cor castanha; o corpo do vestido e a segunda saia é em brocado forrado cor de rosa; a frente é feita de pregas de crepe cor de rosa; cintura e bandas de veludo cor de castanho" e "Vestido de primavera visto na casa Duboys de Paris; em étamine verde musgo, em parte sarapintado de vermelho; uma pequena saia formada de um lado por quatro

grandes pregas e de outro por um pano unido; na frente, gola e ornatos de veludo verde musgo".

Não foi possível identificar a autoria dessas imagens e tampouco estabelecer se foram encomendadas especialmente para A Illustração ou se provinham de alguma outra revista ilustrada. As pesquisas nas páginas do Le Monde Illustré mostraram-se infrutíferas. De fato, a execução das estampas era bastante modesta para os refinados padrões reinantes no semanário francês e, portanto, para a própria A Illustração. Havia mesmo descompasso entre o que se ofertava e o tom pomposo da nota da redação, típico de Pina, na qual se assegurava que "tudo quanto publicaremos nesta nova seção será executado pelos primeiros artistas de Paris neste gênero, e para isso obtivemos o concurso de uma grande casa editora que entrou em contrato especial com a Illustração" ${ }^{\prime 10}$. Se tal acordo existiu não se sabe, mas o certo é que ele não se efetivou nas páginas do quinzenário.

10 Uma novidade. A Illustração, ano 2, n. 8, p. 126, 20 abr. 1885. 


\section{"A moda parisiense"}

Foi somente em 1890, portanto quando a revista luso-brasileira entrou no seu penúltimo ano de circulação e já sem apresentar grandes inovações em termos de seções ou de colaboradores, que o tema moda voltou a ocupar as páginas d'A Illustração com o surgimento de "A moda parisiense". Sua estreia, que ocorreu sem prévio aviso, deu-se em março. Diferentemente do que se observou em 1885, agora se tratava de uma página inteira, com ilustrações cuidadosamente dispostas entre o texto, o que denotava especial atenção à diagramação.

Conforme atestam as figuras 4, 5 e 6, a monotonia dos sólidos blocos tipográficos foi quebrada pela presença de estampas que ocupavam o espaço de uma ou mais colunas, o que dotava a página de certo dinamismo, sem contudo subverter integralmente a sua estrutura. Em outros termos, as colunas seguiam impávidas como elementos fixos, substituindo-se conteúdo escrito pelo visual. Transgredia-se o modelo imperante nas ilustrações, que previa, de um lado, as estampas produzidas com esmero, ricas em detalhes e de dimensões avantajadas, e, de outro, o texto que lhe correspondia. 0 resultado tanto recuperava práticas anteriores, afinal a reunião na mesma página do lápis e da pena estava longe de ser uma novidade, quanto apontava para o que seria a futura fórmula da reportagem, que fez o sucesso das revistas ilustradas na era da reprodução direta da fotografia.

É significativo que oito, de um total de dez ocorrências da seção de A Illustração, apresentassem esse padrão, enquanto apenas duas seguiram o modelo dominante já descrito, com estampas e comentários apartados por várias páginas. Pode-se argumentar que, pela própria natureza do conteúdo, a separação entre texto e imagem não se mostrava muito eficiente, pois os trajes demandavam explicações, ainda que não se tratasse de fornecer um roteiro para a sua produção, objetivo que nunca esteve no horizonte da revista de Pina. É provável que, no caso das duas exceções, houvesse a intenção de nobilitar esse conteúdo em sintonia com a compreensão da diagramação então em voga nessas publicações.

É evidente que a forma e a rama tipográficas eram idênticas no Le Monde e n'A Illustração, apenas os comentários em francês eram substituídos por outros em português, o que resultava em idêntica mise en page nos dois impressos. 
FIGURAS 4, 5 E 6 - EXEMPLOS DE MISE EN PAGE DA SEÇÃO “A MODA PARISIENSE”
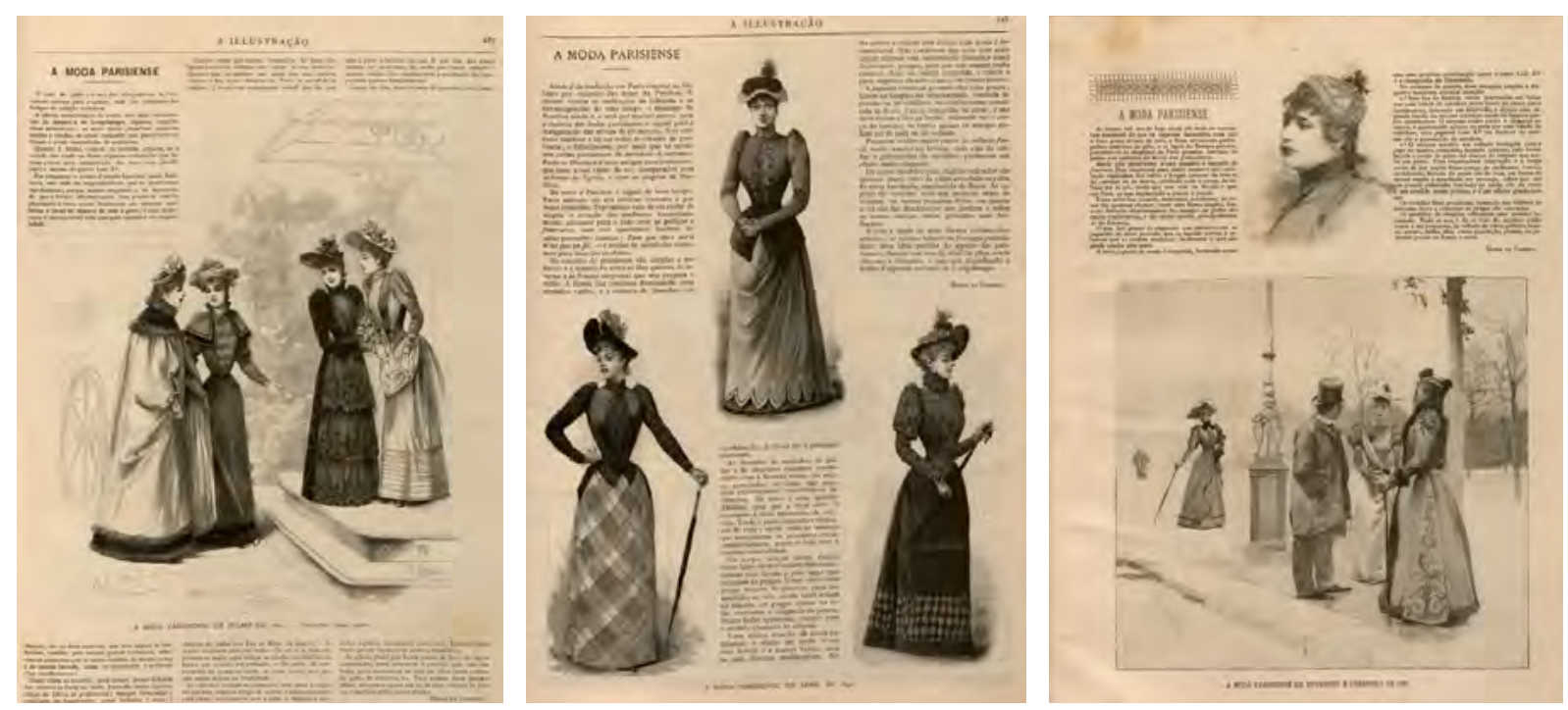

FONTE: A Illustração, ano 7, n. 3, p. 125, 20/4/1890 (figura 4); A Illustração, ano 7, n. 6, p. 237, 5/8/1890, p. 237 (figura 5); e A Illustração, ano 7, n. 10, p. 381, 31/12/1890. Biblioteca da FCL/Unesp (Assis). Para o Le Monde Illustré, consultar, respectivamente, os seguintes endereços: https://gallica.bnf.fr/ark:/12148/ bpt6k6382671w/f13; https://gallica.bnf.fr/ark:/12148/bpt6k6228894j/f13; e https://gallica.bnf.fr/ ark:/12148/bpt6k6382691n/f17. Acesso em: jul. 2018.

É possível argumentar que, pelo menos nesse gênero de impresso, a presença do conteúdo de moda acabou por propiciar deslocamentos na organização do conteúdo no Le Monde Illustré, uma vez que novamente reuniu-se e se colocou em diálogo, no interior de uma mesma página, material textual e iconográfico. Ainda que de maneira tímida, começava-se a ensaiar outras experiências de visualidade e possibilidade de ordenação do layout, que conheceu alterações de monta quando a reprodução direta da fotografia impôs-se como prática corriqueira nos impressos periódicos, com as capturas de instantâneo e as reportagens fotográficas ${ }^{11}$.

Em A Illustração, "A moda parisiense" deixou de ser uma seção e voltou a compor "As nossas gravuras" a partir do ano de 1891 e assim permaneceu até o encerramento da publicação, em janeiro de 1892, circunstância que não alterou o fato de a composição da página continuar a ser uma réplica da revista francesa, ora trazendo apenas estampas, ora entremeando-as com textos que, vale destacar ainda uma vez, não lhe diziam respeito. Dessa forma, exceção feita ao ano de 1890, o leitor lusófono, precisava consultar "As nossas

\footnotetext{
11 Sobre as relações entre reproduções mecânicas e manuais nos impressos ilustrados e o sistema de valores que as cercava, ver: GRETTON, 2007, p. 34-49.
} 
gravuras" para obter informações sobre o significado das estampas consagradas à moda, enquanto no Le Monde o escrito e o visual, na grande maioria das vezes, interagiam, uma vez que compartilhavam o mesmo espaço.

Conclui-se, portanto, que na revista luso-brasileira a experiência foi curta, o que não ocorreu na congênere francesa, que continuou por anos a fio a manter uma seção especialmente dedicada à moda, inclusive com experiências mais ousadas em termos de diagramação. A figura 7 é interessante por exemplificar o recuo do texto em prol da estampa, que se espraia para além da rígida divisão tripartite da página. Se, na revista francesa, o que se lia dizia respeito ao que se via, no exemplar de $A$ Illustração tal integração não mais existia e isso em razão de "A moda parisiense" ter perdido seu estatuto de seção, assumindo a condição de simples estampa acompanhada por breves comentários em "As nossas gravuras". Ainda que de forma bem mais modesta e sintética, continuava-se a cumprir o compromisso de dar a conhecer o que se passava em Paris.

\section{FIGURA 7 - DIAGRAMAÇÃO MENOS RÍGIDA DA PÁGINA}

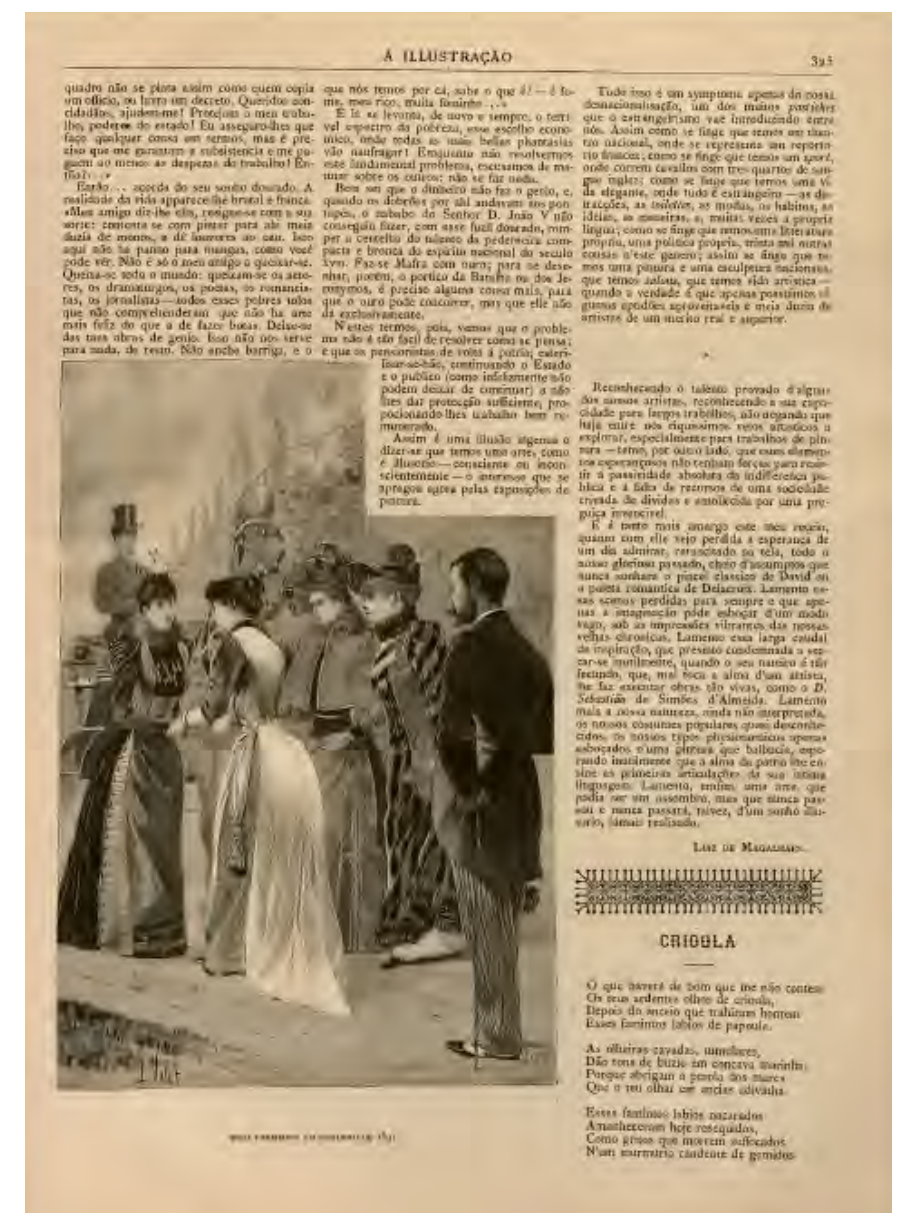

FONTE: A Illustração, ano 8, n. 181, p. 325, 10/10/1891. Biblioteca da FCL/Unesp (Assis). Para o Le Monde Illustré, consultar: https://gallica.bnf.fr/ark:/12148/bpt6k6223108t/f12. Acesso em: jul. 2018. 
A decisão de extinguir a seção pode ser relacionada ao trabalho envolvido na tradução e/ou na adaptação do alentado texto que acompanhava os trajes, o que implicava em mais um tarefa para Pina que, até onde se sabe, não nutria pela moda particular interesse, aspecto que pode tê-lo levado a abandonar o padrão vigente no Le Monde. Contudo, o fato decisivo talvez deva ser creditado à sua trajetória pessoal, pois, em dezembro de 1890, ele assumiu a direção do jornal lisboeta $O$ Nacional, que circulou até setembro do ano seguinte, o que deve tê-lo obrigado a reduzir significativamente o tempo dedicado à Illustração.

\section{O conteúdo: apropriações e adaptações}

As estampas de moda presentes em A Illustração não só eram idênticas às do Le Monde, mas também publicadas quase simultaneamente, o que convida a averiguar como elas foram apresentadas aos leitores lusófonos.

Um aspecto chama a atenção de saída: nas duas publicações, os textos vinham assinados por nomes femininos, mas que não remetiam a figuras identificáveis: Marie de Camors e Ludka, respectivamente. No caso luso-brasileiro, a autoria permitia imaginar a existência de uma pessoa encarregada de selecionar os modelos e comentá-los. A referência à França era evidente - o prenome (Marie), a preposição (de), a evocar nobreza, e o sobrenome, que remetia a uma pequena comuna na região da Bretanha (Camors) ${ }^{12}$, escolhas em harmonia com o próprio nome da seção ("A moda parisiense") e com o imaginário que associava o Hexágono e sua capital ao bom gosto e à elegância.

Já no Le Monde, o simulacro foi de outra natureza, com a opção recaindo em uma designação sem significado preciso e utilizada sobretudo como prenome, tampouco aludia à França ou à sua cultura. Pelo contrário, Ludka evocava certo exotismo por remeter às línguas eslavas, enquanto a sonoridade fazia lembrar ludique, o que pode ser interpretado como referência indireta ao tom ameno do conteúdo.

0 título da seção, "La mode dans le monde", também comportava certa ambiguidade, não sendo inverossímil que o leitor fosse levado a supor que se tratasse de alusão ao título do semanário (a moda no Le Monde Illustré). Já no caso de a ênfase de leitura recair na acepção mais comum do termo monde, o objeto seria a moda ao redor do planeta, em uma visada ecumênica a respeito dos hábitos de vestir, isso em um momento em que uma Europa imperialista ocupava diferentes áreas do planeta. Entretanto, bastaria acompanhar alguns números para que as dúvidas se dissipassem, pois a temática efetivamente discutida na seção sempre foi a moda parisiense e aqui le monde aludia à sofisticação do grand monde, tomado como sinônimo de espaços elegantes e requintados. Se moda e Paris eram praticamente sinônimos, não surpreende que os responsáveis pelo Le Monde não considerassem necessário que a titular da seção também evocasse a França. Pelo contrário, uma pitada de exotismo acabava por acrescentar certo charme ao conjunto.

\footnotetext{
12 É provável que o leitor não tivesse essa informação e tampouco é possível afirmar que a escolha tivesse algum significado especial além de remeter à França.
} 
A decisão editorial de lançar uma seção que não figurava em todas as edições ${ }^{13}$ e que era assinada por um pseudônimo pode ser interpretada como indício de que os idealizadores franceses atribuíam-lhe menor grau de importância, hipótese reforçada pela própria escolha da diagramação, o que não deixa de expressar, nas entrelinhas, concepções sobre o que interessaria ao público feminino ${ }^{14}$. Nas duas revistas, moda e Paris compunham um par inseparável, ainda que na publicação de Pina essa articulação assumisse sentidos específicos, tendo em vista o público leitor, e fosse realçada a cada passo, o que obviamente era dispensável para leitores franceses.

Cabe observar que não se tratava de replicar, de forma automática, o conteúdo da revista francesa na luso-brasileira e isto porque Pina levava a cabo um hábil trabalho de mediação, a começar pelo próprio título da seção e pela menção a outra autoria, cuja intenção era sugerir aos leitores que havia alguém responsável pelas escolhas, ainda que não contasse com informações reais ou fictícias sobre essa pessoa, mas apenas um nome alusivo à França, o que ele deve ter considerado elemento suficiente de legitimação em sintonia com valores e apreensões em circulação no mundo social.

O que o leitor não poderia saber é que o conteúdo textual que acompanhava as estampas, atribuído a Marie de Camors, era muito semelhante ao assinado por Ludka, com largos trechos traduzidos literalmente, o que por certo contava com a anuência dos responsáveis pelo Le Monde. Os acréscimos, supressões e modificações tinham em vista o leitor lusófono e os interesses editoriais de Pina, o que por vezes provocava significativos deslocamentos de sentidos em face do original. Em regra, reproduziam-se os comentários relativos às estampas em si, antecedidos e sucedidos por observações destinadas ao público d'A Illustração. A título de exemplo, vale acompanhar como a seção foi apresentada em cada um dos impressos:

Vamos hoje satisfazer um pedido feito por numerosas leitoras da Illustração, publicando nas páginas dessa revista alguns desenhos de moda, aos quais daremos um verdadeiro aspecto artístico. Temos tenção de os acompanhar de um artigo explicativo que será ao mesmo tempo o comentário das toilettes de que apresentarmos os modelos, e uma pequena crônica da moda parisiense.

\footnotetext{
13 Ao longo de 1890, todas as ocorrências da seção "La mode dans le monde" foram replicadas em $A$ Illustração, com pequenos intervalos. Se na revista francesa a legenda indicava tratar-se da moda para o mês de março, por exemplo, em $A$ Illustração assevera-se que aquela era a moda em abril. Apenas a última aparição de 1890 de "La mode dans le monde" foi estampada na revista luso-brasileira em janeiro do ano seguinte, já não como seção independente, mas integrando "As nossas gravuras", tanto que a estampa figurou na capa.

14 Impresso caro e eclético, que adornava lares abastados, a diversificação do conteúdo pode ser entendida como um recurso para atender a diferentes interesses dos membros da família. É fato que a presença de uma seção fixa com conteúdo de moda foi relativamente tardia, pois o Le Monde estava em circulação desde 1853, não sendo fora de propósito imaginar que a decisão também tenha vinculação com a acirrada disputa pelos leitores, uma vez que o mercado francês dispunha de vários impressos com proposta editorial semelhante. Agregar conteúdo de moda, mas sem a preocupação de fornecer moldes ou explicar como dar concretude ao que se apresentava, era um ponto de diferenciação importante, pois se tratava de dar a conhecer o que era elegante e exclusivo, compondo, assim, um aspecto das novidades, objeto central desse tipo de publicação.
} 
Este novo melhoramento, que representa para a Illustração uma importante despesa de colaboração, significa o desejo que tem a empresa de tornar a nossa revista um verdadeiro jornal de família, com leituras e distrações para todos os espíritos. Teremos o maior cuidado em evitarmos a rotina dos jornais de moda, assim como as modas extravagantes ou excêntricas. Não são nem as ridículas excentricidades de amanhã, nem os erros de ontem, que tencionamos registrar nas páginas da Illustração. É a moda de cada mês, a moda da alta sociedade parisiense, a verdadeira moda dos salões de Paris, a que tem por divisa: elegância na simplicidade. Moda bem diferente da maioria dos jornais de moda, que só mostram, ou extravagancias de mau gosto, ou gravuras de toilettes para exportação. Ora o que a Illustração quer tornar conhecido do seu numeroso público feminino é - a moda parisiense.

Este ano a moda parece disposta a uma benevolente indulgência. Nunca uma época foi mais tolerante do que aquela que estamos atravessando. Tudo se usa! A fantasia tem o direito de fazer o que quiser, conservando-se contudo nos limites do bom gosto e das grandes linhas geralmente consagradas. Para as saias, a forma lisa é ainda a mais adotada ${ }^{15}$. (A ILLUSTRAÇÃO, 1890, p. 93)

Nous nous rendons au désir exprimé par un grand nombre des lectrices du Monde Illustré en publiant à cette place quelques dessins de mode auxquels nous avons essayé de donner le cachet le plus artistique possible. Nous avons l'intention de les accompagner chaque fois d'une causerie explicative, qui sera en même temps le commentaire des toilettes dont nous présentons le modèle et une sorte de petite chronique de la mode. Sachant à quel public choisi nous nous adressons, nous aurons le plus grand soin de nous tenir également éloigné de la routine ou de l'outrance des modes tapageuses. Ce ne sont point les excentricités de demain, ni les erreurs d'hier que nous avons l'intention d'enregistrer. C'est la mode du jour, j'entends celle du vrai monde, c'est-à-dire la mode qui a pour divise : l'élégance dans la simplicité.

La saison à Paris retarde de plus en plus. Nos belles châtelaines ne sont pas encore toutes rentrées, cependant les portes de quelques salons se sont déjà rouvertes et la vie mondaine va bientôt reprendre son animation. Cette année, Sa Majesté la Mode, cette reine capricieuse et tyrannique, semble disposée à une bienveillante indulgence.

Jamais époque n'a été plus tolérante que celle que nous traversons. Tout se porte. La fantaisie a le droit de se donner pleine carrière, en restant toutefois dans les limites du bon goût et des grandes lignes généralement admises. Pour les jupes, la forme plate est encore adoptée par le plus grand nombre ${ }^{16}$. (LE MONDE ILLUSTRÉ, 1890, p. 61)

${ }^{15}$ CAMORS, Marie de. A moda parisiense. A Illustração, ano 7, v. 6, n. 6, p. 93, 20 mar. 1890.

16 LUDKA. La mode dans le monde. Le Monde Illustré, 34e année, n. 1713, p. 61, 25 jan. 1890. Todas as traduções são minhas. 
A comparação é reveladora A despeito de a nota vir assinada por Marie de Camors, afirmava-se que o "melhoramento" implicava em significativos custos para a empresa, detalhe que revela a mão de Pina, uma vez que o tema não seria tratado por e tampouco era da alçada de um colaborador. Se, no Le Monde, o que se colocava em relevo era a moda cotidiana, em A Illustração, pelo contrário, evocava-se a da "alta sociedade parisiense". Tampouco se perdia a oportunidade de criticar, no mesmo diapasão de 1885 , as publicações especializadas no assunto, em um esforço para distinguir e enobrecer o conteúdo de moda ofertado n'A Illustração, o que revela a apreensão que o editor tinha de sua publicação, mas também a difusão de mecanismos de distinção social. Por vezes, o texto mudava de significado, como se observa no seguinte trecho:

Ainda é da tradição em Paris renovar as toilettes por ocasião das festas da Páscoa. E mesmo contra as indicações da folhinha e as intransigências do mau tempo, o domingo de Páscoa ainda é, e será por muitos anos, para a maioria das lindas parisienses, o sinal para a inauguração das modas de primavera. Este costume também é lei em todas as cidades de província; e dificilmente, por mais que se revoltem certas parisienses da novidade à outrance, Paris se libertará destes antigos usos femininos, que tem a sua razão de ser, comparados com as festas da Igreja, e com as alegrias da Páscoa.

De resto a Páscoa é sinal de bom tempo, Paris saindo do seu inverno cinzento e por vezes tristonho. 0 primeiro raio de sol enche de alegria o coração das mulheres. Imediatamente atiramos para o lado com as peliças e fourrures, sem nos lembrar do sábio provérbio francês: Tant que dure avril n'ôte pas um fil - e avidas de novidades corremos para casa das modistas. Os vestidos de primavera são simples.... ${ }^{17}$. (A ILLUSTRAÇÃO, 1890, p. 93)

Autrefois pour la fête de Pâques il était en usage de renouveler sa toilette. En dépit du calendrier et de la mobilité de cette date, ce jour-là marquait le signal de l'apparition des modes du printemps. La coutume en a persisté dans beaucoup de villes de province ; mais à Paris nos tendances vers l'indépendance se manifestent en tout et nous nous sommes affranchies de ces anciens us. Nous nous laissons guider par les caprices de la saison.

Le premier rayon de soleil nous met le cœur en joie et la tête à l'envers. Bien vite, nous rejetons nous fourrures, sans souci du sage proverbe : "Tant que dure avril n'ôte pas un fil", et avides de nouveauté nous accourons chez nos couturières. Les robes printanières sont simples... ${ }^{18}$. (LE MONDE ILLUSTRÉ, 1890, p. 61)

\footnotetext{
17 CAMORS, Marie de. A moda parisiense. A Illustração, ano 7, n. 6, p. 93, 20 mar.1890.

18 LUDKA. Le mode dans le monde. Le Monde Illustré, 34e année, n. 1713, p. 61, 25 jan.1890.
} 
Nesse caso, a apresentação de A Illustração distanciava-se bastante das afirmações de Ludka para reafirmar prática que, na revista francesa, era considerada ultrapassada. Pode-se supor que o objetivo fosse legitimar costume ainda corrente em Lisboa e no Rio de Janeiro, ou simplesmente expressar o ponto de vista divergente de Pina. Afinal, ele morava em Paris desde 1882 e conhecia a rotina da cidade.

Outras vezes, havia acréscimos no fim do texto, em tom de conselho, aspecto distintivo dos impressos dedicados ao público feminino e que configurava pedagogias a respeito da elegância, do bom gosto e do bom-tom, sem deixar de valorizar o material apresentado pela revista:

\begin{abstract}
Mas acima de qualquer descrição minha, têm as leitoras os encantadores desenhos do meu colaborador. Por ai verão o que devem escolher, e o que lhe pode ficar mais a caráter. $\mathrm{O}$ que lhes aconselho é que devem seguir a moda parisiense, que tende cada vez mais a uma extrema simplicidade de toilettes $^{19}$. (A ILLUSTRAÇÃO, 1890, p. 125)
\end{abstract}

\title{
Conclusão
}

Os exemplos poderiam ser multiplicados, mas o rol apresentado permite extrair algumas conclusões. Em primeiro lugar, não se pode perder de vista que Le Monde Illustré e $A$ Illustração inseriam-se em um conjunto particular de impressos, surgido em meados do Oitocentos e cuja circulação estendeu-se, no caso dos mais longevos, por quase um século. Nas páginas dessas publicações estão registradas as mudanças nos processos de produção de estampas, que passaram da fatura artesanal, com atuação de um amplo rol de profissionais, à captura e à reprodução mecânicas, que se impôs no início do século XX. Foi a existência de um mercado de matrizes já utilizadas, as dimensões da indústria gráfica francesa e a agilidade dos transportes marítimos a vapor que permitiram a existência de A Illustração.

No Le Monde Illustré, modelo seguido à risca pela revista luso-brasileira, o conteúdo de moda somente ganhou espaço em 1890, o que ajuda a compreender o insucesso da tentativa de Pina em 1885. A análise da diagramação da página da seção "La mode dans le monde" indicou inovações em relação ao formato consagrado. Pode-se levantar a hipótese que foi justamente a pequena importância da seção no conjunto do impresso que permitiu inovações que retomavam antigas práticas, mas também apontavam para o futuro, uma vez que as reportagens fotográficas, que se imporiam inclusive nesse gênero de periódico, previam justamente a interlocução entre textos e imagens tal como ocorria na seção. Outro dado a ser considerado diz respeito às exigências do assunto, que requeria a interlocução do par texto/imagem de forma mais direta do que outras temáticas abordadas na publicação.

${ }^{19}$ CAMORS, Marie de. A moda parisiense. A Illustração, ano 7, n. 8, p. 125, 20 abr. 1890. 
A Illustração reproduzia o layout da seção tal como figurava no Le Monde, com a substituição da composição textual em francês por outra em português. A atribuição de autoria permite, assim como a mise en page, afirmar a importância secundária atribuída ao conteúdo no conjunto da publicação em ambas as revistas. As supressões, alterações, complementos em relação ao texto original atestam o trabalho de mediação realizado por Mariano Pina, que chegava mesmo a subverter o sentido do original do texto de Ludka. Tal atividade, que deveria tomar tempo significativo, acabou abandonada a partir de 1891, quando a seção perdeu sua independência e passou a integrar "As nossas gravuras".

A análise do material convida a refletir sobre o florescente mercado de circulação de estampas, do qual a moda foi apenas uma das temáticas. Cabe destacar, ainda uma vez, que as matrizes já utilizadas na França eram vendidas por preços reduzidos para os responsáveis pela revista luso-brasileira, o que possibilitava que o preço final de A Illustração fosse relativamente mais barato, tanto frente à congênere francesa quanto em face dos custos de publicações similares lançadas no Brasil ou em Portugal ${ }^{20}$. Em outros termos, não apenas brasileiros e portugueses tinham à disposição o mesmo produto que os franceses, como ainda pagavam valor menor para adquiri-lo. Isto porque era o editor parisiense quem arcava com os custos de produção das estampas, o que incluía os direitos autorais de desenhistas e gravadores. De posse de uma grande quantidade de material que rapidamente tornava-se obsoleto, qualquer ganho adicional era vantajoso, circunstância que ajuda a compreender a decisão de fazer a impressão da revista em uma empresa francesa e mandá-la para os países onde seria, de fato, lida.

É importante notar que, no Le Monde Illustré, havia a preocupação de identificar os responsáveis pela confecção das estampas, o que era feito nas legendas ou nas descrições presentes na seção "As nossas gravuras”, prática bem menos frequente na revista luso-brasileira. Seus responsáveis não tinham contato com os artistas, uma vez que a compra do direito de reprodução dos clichês era feita junto ao impressor, liberando o adquirente de qualquer outro ônus.

A grande proximidade entre A Illustração e o Le Monde ajuda a compreender a livre apropriação do conteúdo textual que, no caso específico do conteúdo de moda, era facilitado pela ausência de autoria - afinal quem era Ludka? - e, ainda, pela inexistência de acordos internacionais de direitos autorais. A publicação luso-brasileira, que chegava regularmente do porto de Bordeaux, permitia que se compartilhasse um imaginário comum a respeito das noções de moda e elegância, uma vez que as mesmas estampas estavam disponíveis, simultaneamente, dos dois lados do Atlântico. A moda foi um dos aspectos difundidos pela revista e talvez pudesse ser elencado entre os mais modestos. Não se deve perder de vista, contudo, que a seção somava-se à profusão de imagens sobre Paris e a França, não sendo despropositado afirmar que A Illustração também colaborou para a duradoura fascinação e o encantamento que o país e sua capital exerceram no seio das elites luso-brasileiras.

\footnotetext{
20 No Brasil, os leitores da Corte despendiam $12 \mathrm{mil}$ réis pela assinatura anual de A Illustração. A título de comparação, vejam-se os valores do último número da Ilustração Brasileira, datado de abril de 1878, ou seja, seis anos antes do lançamento d'A Illustração, cuja subscrição anual montava a $14 \mathrm{mil}$ réis no Rio de Janeiro. Em Portugal, a assinatura anual de A Illustração valia 2.400 réis, bem menos do que se pagava pelo 0 Ocidente, cujo preço da subscrição anual, em maio de 1884, estava em 3.800 réis.
} 


\section{Referências}

\section{Bibliografia}

A ILLUSTRAÇÃO. Paris: 1884-1891.

CHARLE, Christophe. Le siècle de la presse (1830-1939). Paris: Seuil, 2004, 415 p.

GRETTON, Tom. Le statut subalterne de la photographie. Étude de la présentation des images dans les hebdomadaires illustrés (Londres, Paris, 1885-1910). Études Photographiques, n. 20, p. 34-49, juin 2007. Disponível em: http://journals.openedition.org/etudesphotographiques/927. Acesso em: jul. 2018.

LE MOBDE ILLUSTRÉ. Paris, 1857-1940.

LUCA, Tania Regina de. A ilustração (1884-1892): circulação de textos e imagens entre Paris, Lisboa e Rio de Janeiro. São Paulo: Unesp, Fapesp, 2018.

PERROT, Michelle. Maneiras de morar. In: PERROT, Michelle (org). História da vida privada. Da Revolução Francesa à Primeira Guerra Mundial. São Paulo: Companhia das Letras, 2009, v. 4, p. 284-301. 